\title{
LA TOMOGRAFÍA Y LA MICROSCOPÍA CONFOCAL APLICADAS AL ESTUDIO DE PATOLOGÍAS RETINIANAS
}

\section{TOMOGRAPHY AND CONFOCAL MICROSCOPY IN THE STUDY OF RETINAL PATHOLOGIES}

\author{
CUENCA N ${ }^{1}$, PINILLA I ${ }^{2}$
}

La tomografía de coherencia óptica (OCT) es hoy en día una herramienta fundamental en la práctica clínica. Basándose en el principio de la inferometría, proporciona cortes bi- o tridimensionales, midiendo el retraso en la transmisión de los ecos y la cantidad de luz absorbida o reflectada. Con ello se consigue una biopsia óptica proporcionando información sobre la patología retiniana en tiempo real. Desde su desarrollo en 1991, su introducción ha revolucionado las pruebas de imagen en el campo de la oftalmología, y la ha hecho indispensable no sólo para el diagnóstico de determinadas patologías sino incluso para la toma de decisiones terapéuticas. La OCT se ha instaurado como un método diagnóstico insustituible en multitud de patologías oftalmológicas, incluyendo las patologías maculares, el glaucoma y otras patologías neurooftalmológicas.

En los últimos años hemos asistido a grandes cambios en la adquisición de la imagen, apareciendo aparatos de dominio espectral o Fourier. Esta nueva generación de OCTs tiene la ventaja de poder medir ecos luminosos con diferentes retrasos de modo simultáneo lo que aumenta la velocidad de adquisición de la imagen y proporciona imágenes de mayor resolución y más reproducibles. El aumento de la velocidad de adquisición de la imagen reduce los artefactos producidos por el movimiento ocular y mejora la delimitación de las distintas capas de la retina. Además es una técnica inocua para el paciente, rápida y que genera pocas molestias y de gran fiabilidad y reproducibilidad. La tomografía de dominio espectral nos proporciona unas imágenes de una calidad que permite diferenciar las distintas capas neuronales de la retina, incluyendo la capa de células ganglionares, los fotorreceptores y el epitelio pigmentario de la retina (EPR).

La tomografía de coherencia óptica es una ayuda no sólo en la clínica sino también en la investigación de diversas patologías, incluso en modelos animales. La capacidad que tienen alguno de los tomógrafos de identificar la región donde han tomado imágenes en exploraciones previas nos ayuda a valorar cambios temporales a nivel de las capas retinianas. Lo cierto es que con los tomógrafos de dominio espectral se puede identificar, sin problemas, las capas retinianas. De esta forma se puede observar la interfase vítreo-retiniana, la limitante interna, la capa de fibras nerviosas de la retina, las células ganglionares, la plexiforme interna, capa nuclear interna, la plexiforme externa, la capa nuclear externa y la limitante externa, e identificar también los segmentos internos de los fotorreceptores, su unión con los segmentos externos, la capa de epitelio retiniano de la retina, y según el aparato y su capacidad de reconocer las señales coroideas, la coriocapilar y la capa de grandes vasos. La información proporcionada a nivel anatómico impresiona teniendo en cuenta la gran velocidad de adquisición.

Sin embargo, los datos adquiridos mediante OCT son complementarios a la información que nos proporciona el estudio histológico, y que en ninguna manera deja relegada una buena imagen anatómica.

El mantenimiento de la correcta estructura y disposición anatómica neuronal no implica que estas células sean funcionales ni que sean capaces de establecer contactos sinápticos entre ellas. Sí es cierto que la desaferentización provoca con el tiem-

\footnotetext{
${ }^{1}$ Departamento de Fisiología, Genética y Microbiología. Universidad de Alicante. España.

E-mail: cuenca@ua.es

2 Servicio de Oftalmología. Hospital Universitario Miguel Servet. Zaragoza. Instituto Aragonés de Ciencias de la Salud.

E-mail: isabel.pinilla@telefonica.net
} 
po una pérdida neuronal pero en los primeros estadíos una retina que en una imagen tomográfica mantiene una configuración y un espesor normal no tiene porqué ser capaz de realizar una buena función transmisora de la información visual.

Los estudios inmunocitoquímicos utilizando microscopía confocal, además de proporcionarnos datos detallados sobre la estructura de la célula, su disposición, su morfología, la disposición y forma de sus terminaciones dendríticas y axónicas, la localización de su cuerpo celular y su relación con otras células... son imprescindibles para conocer si estas células establecen contactos sinápticos entre ellas. La localización de varios anticuerpos frente a proteínas o marcadores pre y postsinápticos nos dicen si las distintas neuronas establecen contactos sinápticos adecuados y si están en condiciones transmitir correctamente la información a la siguiente estación sináptica.

Varios son los cambios que se producen en la conectividad sináptica entre neuronas en estadios iniciales de algunas enfermedades, como la Retinosis Pigmentaria u otras patologías retinianas degenerativas. Estos cambios pueden detectarse con microscopía confocal o microscopía electrónica en momentos en los que no se observa ninguna modificación ni oftalmoscópica ni a nivel tomográfico, siendo la microscopía fundamental para conocer el estado real de la retina y la efectividad de determinadas terapias. También y gracias al empleo de distintos anticuerpos se puede conocer el estado de la barrera-hematorretiniana, la forma y disposición de las tight junctions a nivel de epitelio pigmentario, y su disposición sobre la membrana de Bruch, la disposición de drusas... Además, en estadios avanzados de las patologías, la remodelación retiniana que ocurre secundaria a la pérdida la población neuronal y el intento de las neuronas residuales de establecer contactos sinápticos con las que todavía funcionan, las modificaciones en los patrones vasculares intrarretinianos, o los cambios en la población glial, también resultan imposible de reconocer con la tomografía ya que, prácticamente, es imposible reconocer las capas de la retina. El estudio histológico de las numerosas patologías dentro de enfermedades neurodegenerativas hereditarias, como la retinosis pigmentaria, es imprescindible a la hora de realizar un pronóstico de la evolución de la enfermedad en cada mutación específica.

Otra limitación de los tomógrafos, que se solucionará con el tiempo, es el tamaño del área estudia- da. En las preparaciones anatómicas podemos hacer cortes de la retina completa observando cambios de retina central a periferia, y estudiar el estado neuronal en montajes de retina entera.

Hace pocos años era difícil imaginar que unas pruebas complementarias como la tomografía de coherencia óptica fueran a aportarnos semejante cantidad de información y ayudarnos tanto al diagnóstico como al seguimiento del paciente. Tampoco nos imaginábamos que su introducción en la investigación nos fuera a ser imprescindible, y con la ventaja indudable de que no es preciso el sacrificio del animal para su seguimiento. Sin embargo, y en el campo de la investigación, queremos insistir en que se trata de una prueba imprescindible pero complementaria a un estudio histológico detallado, y que es imposible que pueda relegar la función de neuromorfólogo especializado en el estudio de los tipos neuronales retinianos y de los contactos interneuronales ya que, sin duda alguna, nos proporcionan datos estructurales fundamentales y parte de ellos tienen una clara traducción funcional. Por último, una limitación para los estudios histológicos es la disponibilidad de material humano por lo que sería imprescindible encontrar la forma adecuada de colaboración entre clínicos e investigadores a la hora de realizar estos estudios.

\section{BIBLIOGRAFÍA}

1. Cuenca N, Pinilla I, Sauvé Y, Wang S, Lu B, Lund RD. Regressive and reactive changes in the connectivity patterns of rod and cone pathways of $\mathrm{P} 23 \mathrm{H}$ transgenic rat retina. Neuroscience 2004; 127: 301-317.

2. Cuenca N, Pinilla I, Sauvé Y, Lund R. Changes in synaptic connectivity following progressive photoreceptor degeneration in RCS rats. Eur J Neurosci 2005; 22: $1057-$ 1072.

3. Marc RE, Jones BW, Watt CB, Strettoi E. Neural remodeling in the retinal degeneration. Prog Ret Eye Res 2003; 22: 607-655.

4. Pinilla I, Cuenca N, Sauvé Y, Wang S, Lund RD. Preservation of outer retina and its synaptic connectivity following subretinal injections of human RPE cells in the Royal College of Surgeons rat. Exp Eye Res 2007; 85: 381-392.

5. Pons M, Garcia-Valenzuela E. Redefining the limit of the outer retina in optical coherence tomography scans. Ophthalmology 2005; 112: 1079-1085.

6. Sandberg MA, Brockhurst RJ, Gaudio AR, Berson EL. Visual acuity is related to parafoveal retinal thickness in patients with retinitis pigmentosa and macular cysts. Invest Ophthalmol Vis Sci 2008; 49: 4568-4572.

7. Strettoi E, Pignatelli V. Modifications of retinal neurons in a mouse model of retinitis pigmentosa. Proc Natl Acad Sci U S A 2000; 97: 11020-11025. 